\section{AB1218-HPR EFFECTIVENESS OF PLATELET-RICH PLASMA ON FUNCTION AND PERFORMANCE IN PATIENTS WITH KNEE OSTEOARTHRITIS: PRELIMINARY RESULTS}

D.C. Sarac ${ }^{1}$, B. Unver ${ }^{2}$, S. Cekmece ${ }^{2}$, M. Erduran ${ }^{3} .{ }^{1}$ Division of Physiotherapy and Rehabilitation, Faculty of Health Sciences, Izmir Katip Celebi University;

${ }^{2}$ School of Physiotherapy and Rehabilitation; ${ }^{3}$ School of Medicine, Department of Orthopaedics, Dokuz Eylul University, Izmir, Turkey

Background: Osteoarthritis is one of the most painful conditions and the most frequent cause of functional limitation and disability. There are variety of methods used in osteoarthritis $(\mathrm{OA})$ treatment, including, physical therapy, exercise, intraarticular injections, surgery, etc. Platelet-rich Plasma (PRP) is a relatively new autologous biologic treatment that is used for stimulating cartilage healing process and improving the symptoms. Although the effects of PRP injection on pain and function investigated before, as to our knowledge there are no studies related to performance.

Objectives: Aim of this study was to investigate effectiveness of PRP on improving function and performance in patients with knee osteoarthritis.

Methods: This study included 28 patients ( $16 \mathrm{~F}, 12 \mathrm{M}$ ) who were affected by grade 1-3 bilateral knee OA according to Kellgren-Lawrence Scale. Patients received three injections of PRP that were performed at monthly intervals by the same doctor. All patients were evaluated before and six months after the first injection. Primary outcome measures were: Stair Climbing Test (SCT), 50-Foot Walk Test (50 FWT), 30-sec Chair Stand Test (30 CST) and Timed Up and Go Test (TUG), IOWA Score. Additionally, Hospital for Special Surgery Score (HSS) was also recorded as a secondary outcome measure. Wilcoxon signed-rank test is used for interpreting the differences between before and after the injections. Results: All patients completed the study with no adverse effects. The mean age of the patients were $59 \pm 7.66$ years. Improvements were determined for all outcome measures after 6 months regard to baseline results $(p<0.01)$ (Table 1$)$.

Table 1. Comparision of Primary and Secondary Outcomes at Baseline and After 6 months

\begin{tabular}{lccc}
\hline & Before & 6 Months After & $P^{\star}$ \\
& Median (IQR 25/75) & Median (IQR 25/75) & \\
\hline Stair Climbing Test & $16(10.55 / 19.75)$ & $13.1(9.25 / 16.75)$ & 0.001 \\
50-Foot Walk Test & $29.5(27.0 / 32.45)$ & $27.26(25.1 / 30.32)$ & 0.001 \\
30-sec Chair Stand Test & $10.5(9.25 / 14.0)$ & $12.5(10.1 / 15.75)$ & 0.001 \\
Timed Up and Go Test & $9.25(7.25 / 14.5)$ & $8.1(6.58 / 10.15)$ & 0.001 \\
lOWA Score & $10.2(8.92 / 12.87$ & $9,9(8.12 / 10.75)$ & 0.008 \\
HSS Right & $63.5(55.0 / 75.0)$ & $75(66.0 / 66.75)$ & 0.001 \\
HSS Left & $66.5(55.25 / 79.25)$ & $78.5(70.0 / 85.0)$ & 0.001 \\
\hline
\end{tabular}

Wilcoxon signed-rank test. IQR: Interquartile Range, HSS Right: Hospital for Special Surgery Score of right knee, HSS Left: Hospital for Special Surgery Score of left knee. ${ }^{*} p<0.05$.

Conclusions: Our preliminary findings show that PRP is safe and effective autologous biologic agent that might improve function and performance in patients with mild to moderate knee OA and; could be considered as a treatment option in patients with knee OA.

Disclosure of Interest: None declared

DOI: 10.1136/annrheumdis-2017-eular.5952

\section{AB1219-HPR EXPERIENCES OF SWEDISH "PAIN SCHOOL - COMPETENCE FOR LIFE" OF PATIENTS WITH CHRONIC WIDESPREAD PAIN - A QUALITATIVE INTERVIEW STUDY}

C. Goksör ${ }^{1,2}$, A. Bergenheim ${ }^{1,3}$, K. Mannerkorpi ${ }^{1} .{ }^{1}$ Neuroscience and Physiology, Gothenburg University, Sahlgrenska Academy; ${ }^{2}$ Närhälsan Frölunda Rehab, Gothenburg; ${ }^{3}$ Närhälsan Uddevalla Rehab, Uddevalla, Sweden

Background: Chronic pain is generally associated with low activity level, low work capability, and negative health consequences (1). Education and exercise have shown effective results for patients with chronic pain (2), and is according to EULAR 2016 recommendations first line interventions for patients with fibromyalgia (3). This educational program "Pain school - Competence for life" for patients with chronic pain was developed by the Swedish Rheumatoid Association together with health care professionals for use in primary health care, but is not previously evaluated. The pedagogy is based on a biopsychosocial perspective and self-efficacy with the purpose to provide knowledge, experience and skills within pain, balance of daily living and physical activity. The program comprises four educational group sessions and 10 weeks of physical activity.

Objectives: To gather deeper knowledge about how patients with chronic widespread pain experienced participation in the Pain school-Competence for life", with focus on changes in perception of pain and/or lifestyle.

Methods: 12 women (age 25-72 years) with chronic widespread pain were included in this qualitative interview study set in primary health care. Informed consent were signed by all participants. Semi-structured individual interviews were held 10 weeks after completion of four educational group sessions. Interviews were conducted by two authors and transcribed verbatim.

Results: One theme and four categories were identified. An overarching theme, describing the participants' experiences of the educational program, was a meaningful learning process. It covered four categories: increased understanding of body and mind, new strategies and ways of thinking, experienced value of participation, and preconditions for change. Participants described increased knowledge, awareness and acceptance relating to their symptoms and limitations.
They expressed new strategies relating to managing pain, physical activity, and everyday life. Both individual and social value of participation was described, such as increased well-being, decreased anxiety and improved relationships. Group dynamics, structure of education and former knowledge was described to predispose change in perception of pain and lifestyle.

Conclusions: The results provide deeper knowledge about patients' experiences of the educational program Pain School Competence for life. The educational program appears to provide a meaningful and well-functioning structure for education for patients with chronic widespread pain in primary health care. Further, this can contribute to improve education and rehabilitation for patients with CWP provided by physiotherapists and occupational therapists in primary health care.

References:

[1] Harker J, Reid KJ, Bekkering GE, Kellen E, Bala MM, Riemsma B, et al. Epidemiology of chronic pain in denmark and sweden. Pain Res Treat. 2012; 1-30.

[2] Hassett AL, Williams DA. Non-pharmacological treatment of chronic widespread musculoskeletal pain. Best Pract Res Clin Rheumatol. 2011;25: 299-309.

[3] Macfarlane GJ, Kronisch C, Dean LE, Atzeni F, Häuser W, Fluß E, et al. EULAR revised recommendations for the management of fibromyalgia. Ann Rheum Dis. 2016;0: 1-11.

Disclosure of Interest: None declared

DOI: 10.1136/annrheumdis-2017-eular.4058

\section{AB1220-HPR THE LEVEL OF ADHERENCE OF RHEUMATOLOGY PATIENTS IN SLOVENIA}

D. Stanković, M. Pavic Nikolic, A. Hočevar. Department of Rhematology, University Medical Centre Ljubljana, Ljubljana, Slovenia

Background: Patient adherence is one of the central factors associated with the control of patient's symptoms, good functional ability and longevity. Health care professionals have significant role in their daily practice to improve the adherence to medications.

Objectives: We aimed to assess the adherence of patients treated at our secondary/tertiary rheumatology center.

Methods: Data were collected in a prospective manner. We investigated the level of self-reported adherence to treatment in 115 consecutive patients (81 women; mean age (SD) of $56.5 \pm 14.7$ years) with systemic inflammatory diseases in December 2016. We used the 19-item questionnaire-Compliance-Rheumatology (CQR).

Results: We found optimal adherence in $52 \%$ of patients: the average (SD) adherence rate was $71.1 \pm 9.42$. We didn't find any significant differences between adherent and nonadherent patients regarding patient age, gender, the diagnosis of rheumatic disease and disease duration time, however, patients with higher education level (at least graduate level) were more compliant than those without any formal education $(p=0.006)$. In addition there was no association between adherence and the type of medication (csDMARD, bDMARD) $(p=0.39)$. Patient data are presented in the table 1.

Table 1. The adherence according to the patient diagnosis

\begin{tabular}{|c|c|c|c|c|c|c|c|}
\hline \multicolumn{2}{|c|}{ Diagnosis, n (\%) } & \multirow{3}{*}{$\begin{array}{c}\text { Disease duration, } \\
\text { year }\end{array}$} & \multirow{3}{*}{$\begin{array}{c}\text { CQR total score, } \\
\text { mean (SD) }\end{array}$} & \multicolumn{4}{|c|}{ CQR quartiles, $\mathrm{n}(\%)$} \\
\hline & & & & \multicolumn{2}{|c|}{$\begin{array}{c}\text { Least adherent } \\
\mathrm{n}(\%)\end{array}$} & \multicolumn{2}{|c|}{$\begin{array}{c}\text { Most adherent } \\
\mathrm{n}(\%)\end{array}$} \\
\hline & & & & $<64$ & $64-71,9$ & $71,9-87,9$ & $87,9+$ \\
\hline RA & $65(56 \%)$ & 10,8 & $69,90(9,56)$ & $18(28 \%)$ & $19(29 \%)$ & $28(43 \%)$ & 0 \\
\hline PSA & $14(12 \%)$ & 14,7 & $74,18(10,62)$ & $3(22 \%)$ & $1(7 \%)$ & $10(71 \%)$ & 0 \\
\hline AS & $14(12 \%)$ & 9,7 & $73,43(10,73)$ & $2(14 \%)$ & $3(22 \%)$ & $9(64 \%)$ & 0 \\
\hline Other & $22(20 \%)$ & 12 & $70,81(11,59)$ & $6(27 \%)$ & $3(13 \%)$ & $12(55 \%)$ & $1(5 \%$ \\
\hline
\end{tabular}

Conclusions: Our study showed lower adherence rate than expected. To improve patient adherence we should work more in the future on providing additional knowledge and support to patients.

Acknowledgements: Special thanks to our colleagues Tadeja Šušteršič and Albina Stanovnik.

Disclosure of Interest: None declared

DOI: 10.1136/annrheumdis-2017-eular.3073

\section{AB1221-HPR COMPARISON OF DMARD THERAPIES ON NSAID INTAKE, DISEASE ACTIVITY, FEAR OF MOVEMENT, AND QUALITY OF LIFE IN PATIENTS WITH ANKYLOSING SPONDYLITIS}

G.I. Kinikli ${ }^{1}$, S. Karahan ${ }^{2}$, A. Ates ${ }^{3}$, M. Turgay ${ }^{3}$, G. Kinikli ${ }^{3} .{ }^{1}$ Dept. of Physiotherapy and Rehabilitation, Hacettepe University Faculty of Health Sciences; ${ }^{2}$ Dept. of Biostatistics, Hacettepe University Faculty of Medicine; ${ }^{3}$ Dept, of Rheumatology, Ankara University Faculty of Medicine, Ankara, Turkey

Background: Ankylosing Spondylitis (AS) may result in loss of mobility and function; therefore, patients can experience pain and stiffness with a loss of physical function in addition to severe impairment in their quality of life. Standard treatment of AS consists of nonsteroidal anti-inflammatory drugs (NSAIDs) and physical therapy. 